\title{
Redes sociais e turismo: reflexões no contexto do desenvolvimento regional
}

\section{Social networks and tourism: reflections in the context of regional development}

\author{
Sarah Marroni Minasi (MINASI, S. M.) ${ }^{*}$ e \\ Rogério Leandro Lima da Silveira (SILVEIRA, R. L. L. da) ${ }^{* *}$
}

RESUMO - O estudo das redes sociais é relevante para melhor compreender os atores sociais e suas relações e interações sociais. Assim, procura-se entender o modo como se articulam os atores, os conflitos presentes nas relações sociais, entre outros temas. Neste ensaio se aborda a relação das redes sociais e o turismo. Buscou-se evidenciar as correlações entre a formação de redes sociais, a expansão da atividade turística e o desenvolvimento regional. Apresenta-se como objetivo uma reflexão sobre a relação entre a configuração de redes sociais e os agentes do turismo na dinamização da atividade turística e promoção do desenvolvimento regional. Portanto, esse artigo se constitui em uma discussão teórica baseada na revisão bibliográfica produzida sobre a temática em foco. Notou-se que a revisão do papel de cada agente social do turismo nos processos de apropriação dos territórios turísticos e das redes regionais estabelecidas favorece uma nova instância de gestão para o desenvolvimento do setor. Portanto, ações de cooperação em rede estão diretamente relacionadas com o fortalecimento da gestão no âmbito regional, a descentralização da gestão, e a promoção de dinâmicas do desenvolvimento regional.

Palavras-chave: Turismo; Território; Redes Sociais; Desenvolvimento Regional.

ABSTRACT - The study of social networks is relevant to better understand the actors and their relationships from the social point of view. Thus, we try to understand how the actors are articulated, the conflicts present in social relations, among other subjects. This essay addresses the relationship of social networks and tourism. It was sought to highlight the correlations between the formation of social networks, the expansion of tourism activity and regional development. The objective of this article is to present a reflection on the relationship between the configuration of social networks and the tourism agents in the dynamization of tourism activity and promotion of regional development. Therefore, this article constitutes a theoretical discussion based on the bibliographical review produced on the thematic in focus. It was noted that the review

\footnotetext{
* Formação: Graduação em Turismo (Bacharelado) pela Universidade Federal de Pelotas (UFPel), Mestrado em Desenvolvimento Regional no Programa de Pós-Graduação em Desenvolvimento Regional Universidade de Santa Cruz do Sul (UNISC). Atividade profissional: Professora no Curso de Bacharelado em Turismo na Universidade Federal de Pelotas. Endereço físico para correspondência: Rua Gomes Carneiro, 01 - $4^{\circ}$ andar (Centro). CEP: 96010-610 - Pelotas - Rio Grande do Sul/RS - Brasil. E-mail: sarahminasi@gmail.com

** Formação: Graduação em Geografia pela Pontifícia Universidade Católica do Rio Grande do Sul (PUCRS), Mestrado em Geografia pela Universidade Federal de Santa Catarina (UFSC), Doutorado em Geografia Humana pela Universidade Federal de Santa Catarina (UFSC). Atividade profissional: Professor do Programa de Pós-Graduação em Desenvolvimento Regional - UNISC. Endereço físico para correspondência: Av. Independência, 2293. Sala 1023 - Bloco 10. Bairro Universitário. CEP: 96815-900 - Santa Cruz do Sul - Rio Grande do Sul/RS - Brasil. E-mail: rlls@unisc.br
} 
of the role of each social agent of tourism in the processes of appropriation of tourist territories and established regional networks favors a new management body for the development of the sector. Therefore, networking actions are directly related to the strengthening of regional management, the decentralization of management, and the promotion of regional development dynamics.

Key words: Tourism; Territory; Social Networks; Regional Development. 


\section{INTRODUÇÃO}

Autores como Manuel Castells (2000), Mark Granovetter (1973), Ilse SchererWarren (2007) e Regina Marteleto (2004), buscaram o estudo das redes sociais para melhor compreender aqueles que integram e atuam nas redes e suas relações do ponto de vista social. Assim, passaram a procurar entender o modo como se articulam os atores, os conflitos presentes nas relações sociais, entre outros temas. A partir dos estudos desenvolvidos na grande área das ciências sociais surgiram recursos em termos de pesquisas e estudos os quais abordam as redes sociais das mais diversas formas desde exclusivamente qualitativas até o outro extremo, o quantitativo, passando por formas intermediárias e em conjunto.

As redes sociais configuram-se a partir do interesse entre dois ou mais agentes sociais territorialmente localizados em estabelecer um tipo de relação. Primeiramente, é imprescindível que haja um objetivo comum. Nesse sentido, as redes sociais são imateriais, logo, os fluxos resultantes das interações e relações sociais entre os diferentes agentes sociais são de natureza diversa, constituídos por informações conhecimentos, valores, interesses e esforços em busca de objetivos comuns. (DEGENNE; FORSE, 1999).

A informação é um insumo básico para a geração do conhecimento sobre a realidade e para a ação social e é também de profunda relevância econômica e política. A viabilização das redes deve ser estimulada, visto que, elas somente existem de fato, quando os integrantes ingressam de forma espontânea e se concretiza um fluxo constante de qualquer natureza, seja financeira, informacional ou até mesmo de deslocamento.

Os princípios e modos de funcionamento das redes trabalham para que os diversos atores espalhados em um território possam na medida de suas necessidades e desejos, desenvolver projetos ou ações de cooperação em rede, de forma descentralizada e autônoma (MINISTÉRIO DO TURISMO, 2007).

Por meio das redes se viabilizam cada vez mais articulações, as quais demonstram ser uma forte ferramenta para legitimar e fortalecer ideias e ações. A efetivação das ações está condicionada aos indivíduos ou um agrupamento organizado de indivíduos. Ainda, nas ações pressupõe-se a formatação de uma relação. Contudo, 
observa-se que essa relação nem sempre se dá dentro dos princípios de solidariedade e cooperação positiva, nem sempre é uma relação amistosa, pois é permeada por diferentes interesses. Convém abordar que faz parte do estudo das redes sociais a horizontalidade das conexões, ou seja, a ausência de hierarquia nas relações e interrelações sociais que caracterizam as redes sociais.

Essa que é a característica principal das redes, mas ao mesmo tempo, não é suficiente para garantir a plena participação e democratização nos processos decisórios, uma vez que os graus de participação sempre dependem do interesse dos atores.

No âmbito da gestão, as ações políticas não podem ignorar as informações que os próprios grupos sociais elaboram a partir de seus universos locais de vivência, interação e trabalho. No caso do turismo, existem ações, como por exemplo, o Programa de Regionalização do Turismo, estruturado pelo Plano Nacional de turismo 2013-2016. (MINISTÉRIO DO TURISMO, 2013), o qual incentiva e proporciona as condições e conteúdos adequados à organização de relações de forma não hierárquica e democrática, através da cooperação em redes.

No presente ensaio se tem como objetivo apresentar uma reflexão sobre a relação entre a configuração de redes sociais e os agentes do turismo na dinamização da atividade turística e promoção do desenvolvimento regional. Portanto, esse artigo se constitui em uma discussão teórica baseada na revisão bibliográfica produzida sobre a temática em foco.

O ensaio está assim organizado: Inicialmente, se apresenta uma reflexão sobre os conceitos de redes, território e região. Nessa parte se apresenta o debate sobre a relação entre esses três conceitos chave e sobre a importância do entendimento destes para o processo de desenvolvimento de determinada atividade econômica em um território. Na sequência, na segunda parte se introduz considerações acerca das redes sociais e a importância para o turismo, principalmente na área do planejamento turístico. Se aborda como a formatação de redes sociais pode influenciar na dinâmica de fluxos em um território. A terceira e última parte apresenta, ainda que de modo sucinto, o debate sobre as redes sociais e o turismo, enquanto fenômeno social e atividade sujeita a interesses dos mais variados grupos, como dinamizador do processo de desenvolvimento regional. A exposição de enfoques relevantes dos elementos mais importantes trazidos no corpo do ensaio compõe as considerações finais. 


\section{TERRITÓRIO, REDES E REGIÃO}

Na tentativa de compreender os sentidos das redes sociais e suas relações com um território cabe primeiramente, diferenciá-lo da ideia de espaço geográfico. Por espaço geográfico entende-se o produto de uma relação interdependente entre objetos materiais, podendo ser elencados como objetos geográficos e técnicos, por exemplo, o sistema de transporte ferroviário, e as ações dos sujeitos que moldam o espaço. Santos (2006, p. 69) afirma que:

[...] ao nosso ver, a questão a colocar é a da própria natureza do espaço, formado, de um lado, pelo resultado material acumulado das ações humanas através do tempo, e, de outro lado, animado pelas ações atuais que hoje lhe atribuem um dinamismo e uma funcionalidade. Paisagem e sociedade são variáveis complementares cuja síntese, sempre por refazer, é dada pelo espaço humano.

Um território é o resultado da ação dos homens sobre um espaço, intermediados por objetos naturais e artificiais. Um território é também formado de fixos e de fluxos. Os fixos, são os objetos materiais construídos e fixados no espaço geográfico pelo trabalho social e que possibilitam diferentes usos do território, como são os casos, por exemplo, dos prédios residenciais, comerciais e públicos, os aeroportos e estações rodoviárias, as fábricas etc. Já os fluxos, são o resultado da ação social e se expressam no espaço geográfico, através de diferentes tipos de movimentos como são o caso dos movimentos de pessoas, ou fluxos de migração, os movimentos de produtos e mercadorias, ou fluxos econômicos, os movimentos de capital, ou fluxos financeiros, os fluxos de informação, entre outros. Conforme explica Santos (2006, p. 38), os objetos fixos, fixados em cada lugar, permitem ações que modificam o próprio lugar, fluxos novos ou renovados recriam as condições ambientais e as condições sociais, e redefinem cada lugar. Portanto, os fluxos são resultado direto ou indireto das ações, vezes atravessam, vezes se instalam nos fixos, modificando a sua significação e o seu valor, e simultaneamente também se modificam.

Essa discussão aborda a questão dos agentes sociais e apropriação de um território, o que remete a noção de espaço vivido, em que Santos (2002, p. 10) entende que: 
[...] o território não é apenas o conjunto dos sistemas naturais e de sistemas de coisas superpostas. O território tem que ser entendido como o território usado, não o território em si. O território usado é o chão mais a identidade. Logo, a identidade representa o sentimento de pertencimento, de identificação com o espaço do exercício da vida.

Na mesma linha, Etges (2001, p. 7) complementa que "o território tem que ser visto como algo que está em processo, uma forma-conteúdo, o traço de união entre o passado e o futuro imediato. Ele tem que ser visto como um campo de forças, como um lugar de exercício, de contradições [...]”'. Nesse sentido, Matos (2011, p. 173) afirma que território pode ser híbrido, múltiplo, dinâmico e complexo. E lembra que:

[...] como teorizava Milton Santos: território é o espaço dinâmico, que pode se configurar ou reconfigurar de acordo com o resultado de conflitos entre grupos culturais, classes sociais ou escala geográficas em jogo e mesmo assumir formas híbridas que encerrem dimensões locais e globais, tempos longos e tempos curtos.

A produção de um território, então, se dá a partir da introdução de fluxos e fixos, e para isso é fundamental a existência de redes materiais como as redes de infraestrutura de transportes, de energia, por exemplo, e de redes imateriais, como as redes sociais de cooperação, de informação etc. O processo de produção e valorização de um território pressupõe que este está condicionado e é produto das relações sociais ali presentes.

Flecha et. al. (2012, p. 388), apontam que "originalmente as redes são estruturas abertas capazes de expandirem-se de maneira ilimitada, integrando novos nós, desde que consigam comunicar-se dentro da rede". Nas redes, os nós representam os pontos da rede, todos os elementos que estão conectados. Assim, as redes podem ser definidas como o conjunto de localizações sobre a superfície terrestre, articulado por vias e fluxos e concretizadas pelas interações entre os agentes integrantes. (CORRÊA, 1999).

Logo, os agentes antes dispersos pelo território podem interagir, articulando fluxos materiais ou imateriais. O estabelecimento e organização das redes iniciam sem que seja possível saber a previsão da amplitude que esta irá ter. Cada ator dela componente é um potencial que amplificará as relações. Nesse sentido, a dificuldade em planejar a organização de uma rede é devido estas serem compostas na sua essência por indivíduos. Lencioni (1999, p. 176) explica que: 
[...] essa rede conecta, num instante, os lugares e os homens, redimensionando a percepção de distância. A aproximação virtual sobrepõese à antiga sociabilidade e se constrói uma segunda natureza de relações que, mediatizada pela eletrônica, aproxima lugares e os homens, quebrando o isolamento territorial entre eles.

Nesse sentido, a ideia de redes segundo Dias (2009, p. 148), mostra algumas de suas propriedades:

A primeira propriedade das redes é a conexidade - qualidade de conexo -, que tem ou em que há conexão, ligação. Os nós das redes são assim lugares de conexões, de poder e de referência, como sugere Raffestin. Mas ao mesmo tempo em que têm o potencial de solidarizar, de conectar, também têm de excluir.

As redes são responsáveis pela conectividade e dão suporte aos fluxos dos mais variados tipos. As redes invariavelmente são compostas por fluxos e fixos e apresentam tanto o caráter material como imaterial, devido ao fato de que seu princípio dinâmico é o aspecto social. Dessa forma, por sua propriedade de conexidade, as redes influenciam nos processos de integração, desintegração e de exclusão. (ALVES, 2010).

Portanto, como aponta Dias (2005), uma rede como qualquer outra invenção humana, é uma construção social. Indivíduos, grupos, instituições ou firmas desenvolvem estratégias de toda ordem (políticas, sociais, econômicas e territoriais) e se organizam em rede. Portanto, uma rede não constitui o sujeito da ação, mas expressa ou define a escala das ações sociais. Fratucci (2009, p. 395) ressalta que "pensar as redes como resultado das ações dos agentes sociais e não como sujeitos daquelas ações, nos leva a tirar o foco das redes técnicas e levá-lo para o conjunto das ações dos agentes sociais que engendram aquelas redes".

Na mesma linha, para Santos (2006, p. 176) uma rede "[...] é também social e política, pelas pessoas, mensagens, valores que a frequentam. Sem isso, e a despeito da materialidade com que se impõe aos nossos sentidos, a rede é, na verdade, uma mera abstração". Sua formação se dá a partir da conexão entre seus nós, baseada não em noções de disposição geográfica, mas sim na capacidade dinâmica produzida por este tipo de organização.

A capacidade dinâmica refere-se às relações e ações viabilizadas pela rede. É por meio destas que uma rede está diretamente relacionada com um território, uma vez que, participa dos seus processos de formação. As redes não são o que determina as ações em 
um território, mas são partes integrantes da dinâmica territorial. É nesse contexto que as redes são um instrumento poderoso para a compreensão da dinâmica territorial brasileira. (DIAS, 2009). Como exemplo, pode-se destacar, o papel da rede viária brasileira que possui um dado padrão de localização e de cobertura do espaço geográfico brasileiro, em que as estradas, ferrovias, e hidrovias, articulam ou não os lugares e cidades do país. Um outro exemplo, são as redes sociais de cooperação constituídas no campo e na cidade, que possibilitam o desenvolvimento econômico e social em muitos municípios e regiões do País.

Ao conhecer os processos de formação social de um território, conhecer os fluxos materiais e imateriais torna possível compreender a sinergia e a dinâmica de determinada região. É somente com a compreensão da existência de um território, com o surgimento de uma territorialidade/identidade é que se pode pensar em região e regionalização, se não há entendimento da delimitação de um território, não há regionalização. Uma região, a partir da perspectiva de existir um território deve ser construída socialmente, e envolver traços de identidade. Esses traços estão presentes na cultura, economia e política. Boisier (1994, p. 8) completa que construir socialmente uma região é:

[...] potenciar su capacidad de auto organización, transformando una comunidad inanimada, segmentada por intereses sectoriales, poco perceptiva de su identificación territorial y en definitiva, pasiva, en otra, organizada, cohesionada, consciente de la identidad sociedad-región, capaz de movilizarse tras proyectos colectivos, es decir, capaz de transformarse en sujeto de su propio desarrollo.

Cada vez mais se destaca que as regiões são construídas, consolidadas, transformadas e decompostas por processos de interação social, política e econômica, desenvolvidos ao longo da história (BANDEIRA, 2010). Isto é, ver região como um conceito dinâmico e não como uma categoria que cristaliza os conteúdos do passado (SILVEIRA, 2010).

Cabe evidenciar que as redes têm destaque na construção de novas escalas territoriais, ainda que seu papel não seja determinante, mas de acompanhamento. $\mathrm{O}$ surgimento de uma rede se dá na necessidade de unir, em cooperação, diferentes atores 
e incentivá-los a agir, visando aumentar a coesão e facilitar a busca de objetivos comuns para o desenvolvimento da região que coabitam.

\section{REDE SOCIAL E TURISMO}

A ideia que as relações sociais compõem um tecido que possibilita a ação cooperada dos indivíduos nele inseridos é do início do século XX (MARTELETO; SILVA, 2004). Pesquisadores das ciências sociais na busca da construção de um conceito de redes sociais dialogam com diversas áreas da ciência, perpassando a antropologia, biologia, geografia, entre outros. (SCHERER-WARREN, 2007). Destacam-se duas principais vertentes no estudo das redes sociais: o estudo que busca uma explicação para a estrutura social; e o estudo que busca a descrição das relações sociais. (SCHERER-WARREN, 2007).

Logo, na análise das redes sociais se prioriza grupos, pessoas, instituições que se organizam entre si em busca de informações ou qualquer outro objetivo, desde que tenham interesses em comum. Schlithler (2010) evidencia que no sentido social, uma rede pode ser definida como as relações entre as pessoas, sendo os atores principais as pessoas (os nós, ou laços), e a interatividade entre elas, as relações (ou os fios).

Knupp e Mafra (2012, p. 667), discutem o sentido de rede social como:

[...] um conjunto de atores ligados por relação sociais, ou seja, redes de comunicação que envolve a linguagem simbólica, limites culturais e relações de poder sendo um campo presente em determinado momento, estruturado por vínculos entre indivíduos, grupos e organizações construídos ao longo do tempo (GRANOVETTER et. al ., 2000; CAPRA, 2002 ${ }^{2}$; MARQUES, $2006^{3}$ ). Essa parece ser a morfologia social de nossas sociedades sendo a rede um ambiente da vida social (CASTELLS, 1999 ${ }^{4}$; STEINER, $2006^{5}$ ).

\footnotetext{
${ }^{1}$ GRANOVETTER, M.; CASTILla, E.; HWANG, H. GRANOVETTER, E. Social networks in Silicon Valley. In: LEE, C. M.; MILLER, W. F.; HANCOCK, M. G.; ROWEN, H. S. (Ed.). The Silicon Valley edge. Stanford: Stanford University, 2000. p. 218-247.

${ }^{2}$ CAPRA, F. As conexões ocultas: ciência para uma vida sustentável. 2. ed. São Paulo: Cultrix, 2002.

${ }^{3}$ MARQUES, E. C. Redes sociais e poder no Estado brasileiro. Revista Brasileira de Ciências Sociais, São Paulo, v. 21, n. 60, p. 15-41, fev. 2006.

${ }^{4}$ CASTELLS, M. A sociedade em rede. São Paulo: Paz e Terra, 1999. v. 1.

${ }^{5}$ STEINER, P. A sociologia econômica. São Paulo: Atlas, 2006.
} 
Alves (2010) complementa que é possível também que os membros de uma rede simultaneamente participem de uma ou mais redes sociais e podem manifestar-se em redes de diferentes escalas. Embora existam importantes conexões com outras escalas geográficas, o fator proximidade local delimita um patamar importante de uma rede social (ALVES, 2010).

Dessa forma, a dinâmica de uma rede trata do desenvolvimento das relações no tempo e espaço. Para Matos (2011, p.172):

Rede social é basicamente, um conjunto de relações resultantes da articulação de grupos de pessoas, ou instituições sociais, segundo motivações específicas mais ou menos duráveis no tempo. Uma rede social pode se desdobrar por localidades contíguas ou distantes e aglutinar outras redes sociais.

Alguns exemplos, nesse sentido são as redes de trabalhadores de um dado setor, como o da educação ou da saúde, as redes dos movimentos ambientalistas, as redes dos movimentos sociais urbanos, a rede dos movimentos sociais no campo, ou ainda as redes de migrantes. Todas elas se constituem a partir das relações e interações entre diferentes agentes sociais e instituições localizados em lugares distintos no espaço geográfico, seja no âmbito da cidade, da região, do estado, do país ou do espaço mundial, configurando uma dada dimensão territorial.

A horizontalidade das interconexões é um aspecto elementar no estudo das redes sociais. Talvez o principal diferencial entre uma rede e os demais tipos de organizações é a questão do poder. Uma rede baseia-se num conjunto dinâmico de elementos, por definição, já empoderados e que mantêm entre si relações não hierárquicas. Todos partilham o mesmo grau de poder e é isso o que confere o status de rede a esse tipo de organização. (SCHERER-WARREN, 2007).

Ao contrário dos tipos tradicionais de organização social (cujo organograma é sempre uma variação da forma da pirâmide), nos quais o poder está sempre concentrado em apenas um ou em alguns poucos pontos, a rede opera por meio de um processo de radical desconcentração de poder. A morfologia da rede é uma fonte de drástica reorganização das relações de poder. (CASTELLS, 2000).

A forma de organização das redes sociais permite à sociedade uma estruturação horizontalizada, na qual as relações sociais formam-se sem serem baseadas hierarquicamente, possibilitando que as informações sejam compartilhadas por um 
maior número de indivíduos dentro desta rede, uma vez que a estrutura possui maior autonomia e gestão descentralizada. (ALVES, 2011). Assim, observa-se que as redes a partir de sua organização democrática e horizontal visam promover alguma ação ou mudança de natureza econômica, política, social ou outra. (ALVES, 2011). A rede dos movimentos sociais urbanos pela preservação do patrimônio histórico e urbanístico que se constitui em algumas das cidades brasileiras, tendo como objetivo a preservação da memória urbana e da cultura local através de ações junto ao Estado, é um exemplo a ser citado. Um outro, se refere a rede social dos migrantes pendulares que se movimentam no espaço geográfico, entre distintas cidades, muitas vezes contiguas ou próximas, em busca de trabalho ou de estudo. Nessa rede social, os migrantes pendulares que residem em uma cidade ou na área rural de um dado município, se deslocam diariamente para outra cidade, para trabalhar e/ou estudar, retornando no final do dia, para seu local de moradia. Tais migrantes, nesse percurso diário, interagem e estabelecem relações com agentes sociais e instituições que participam do desenvolvimento de sua atividade de trabalho e de estudo.

No âmbito do turismo, o trabalho em rede constitui um potente recurso, capaz de gerar resultados positivos em resposta aos esforços empreendidos pelos diversos protagonistas envolvidos nas etapas do processo de planejamento e gestão da atividade. A relação das redes e o turismo pode se dar na esfera da oferta, poder público, iniciativa privada e toda a infraestrutura turística e; na da demanda, dos turistas. (FLECHA et al., 2012; KNUPP; MAFRA, 2012).

O setor do turismo é altamente interdependente e o sucesso de uma organização, de certa forma, está intimamente ligado ao sucesso da outra, formando um grupo denominado de rede turística (KNUPP; MAFRA, 2012). A aproximação e a troca de conhecimento entre os participantes fortalecem a ação regional, transformando, uma iniciativa localizada numa prática expansível para outros lugares, e seus resultados ultrapassam os limites geográficos de um município, região, estado ou país.

Por meio das redes e de suas múltiplas conexões, soluções podem ser encontradas e divulgadas, conhecimentos podem ser produzidos e novos rumos são traçados, de modo a estimular o desenvolvimento nas regiões turísticas brasileiras. (MINISTÉRIO DO TURISMO, 2007, p. 14). 
Contudo, Andrighi e Hoffman (2010, p. 162) ressalvam que "a aglomeração territorial, típica das destinações turísticas não é uma condição suficiente para a existência de uma rede interorganizacional”.

A participação e coesão dos atores sociais na elaboração do planejamento turístico e na implantação das estratégias na ordenação da atividade supera a visão estritamente setorial do desenvolvimento. O desenvolvimento de uma região turística será tanto maior quanto mais parcerias entre os protagonistas surgirem (MINISTÉRIO DO TURISMO, 2007). "El turismo se lleva a cabo por la acción, por la articulación y por la interconexión de sus diversos agentes productores en un determinado tiempo y espacio." (FRATUCCI, 2011, p. 1485).

\section{REDES SOCIAIS E TURISMO PARA O DESENVOLVIMENTO REGIONAL}

A partir de uma concepção de desenvolvimento que engloba as particularidades e a perspectiva endógena - que valorize os atributos naturais, culturais e econômicos do território, e o capital social existente de modo a viabilizar o desenvolvimento sustentável da região -, ressalta-se a fundamental importância da coesão das relações dos atores regionais. O desenvolvimento regional implica na conciliação entre os diferentes interesses. Ademais, pressupõe-se uma estrutura que consiga promover um espaço amplo de troca de informações e experiências entre os diversos atores regionalmente localizados.

O desenvolvimento regional no contexto da realidade atual precisa estar atento à dimensão horizontal do processo, conhecer, em profundidade a região em questão, identificar suas potencialidades e construir instrumentos de coesão social em torno de propósitos comuns à população envolvida. Além disso, é preciso criar formas de representação da vontade da maioria, identificada a partir da participação de todos, para permitir que uma nova forma de gestão do território possa ser gestada. (ETGES, 2001, p. 11).

Na ideia de desenvolvimento regional subtende-se a configuração de um tipo de organização democrática e horizontal, ou seja, uma rede social entre os atores. Essa somente poderá ser estabelecida quando houver uma tomada de consciência geral da importância da construção de um projeto político-social, uma busca pela convergência 
dos objetivos e ações, e o despertar da capacidade de formar e fortalecer o desenvolvimento regional.

No caso do desenvolvimento do turismo, Flecha et al. (2010) abordam que a formação de uma rede só é alcançada com o empenho de um número significativo das pessoas envolvidas diretamente com a atividade. Esse esforço somente será alcançado, segundo os autores, se houver uma conscientização geral do grau de importância do turismo como instrumento viável para o desenvolvimento regional. E a partir disso, todos os participantes conscientes dos mesmos objetivos e atuação ativa, têm em mãos a capacidade de fortalecer a sua região.

O Ministério do Turismo - Mtur (2007) apresenta o que é desenvolver o turismo com base em regiões. E para isso, integração e cooperação em busca de uma sinergia na atuação conjunta entre os envolvidos, seja direta ou indiretamente, são vistas como características essenciais.

Regionalizar não é apenas o ato de agrupar municípios com relativa proximidade e similaridades. É construir um ambiente democrático, harmônico e participativo entre poder público, iniciativa privada, terceiro setor e comunidade. (MINISTÉRIO DO TURISMO, 2007, p. 10).

O incentivo à criação de redes sociais no turismo implica em relações entre o setor privado, público e demais entidades relacionadas (ANDRIGHI; HOFFMAN, 2010), além da população residente. Nesse sentido, os atores utilizam a ação cooperativa para aumentar sua competitividade entre regiões turísticas. Uma rede no turismo possibilita que municípios que não são dotados de potencial relevante para induzir o turismo, possam se agregar a outros e evidenciar suas potencialidades e peculiaridades e capacidade produtiva de forma regionalizada. Andrighi e Hoffman (2010, p. 151) comentam que "as redes interorganizacionais são consideradas um incremento nas potencialidades individuais, para desenvolver vantagem competitiva no âmbito coletivo de uma destinação".

Essa cooperação não suprime a competição. Ou seja, no âmbito intra-regional (dentro da destinação), as empresas permanecem competindo umas contra as outras em termos de turistas para a hotelaria ou a restauração, mas no âmbito inter-regional, essas mesmas empresas vão cooperar, para alcançar vantagem competitiva contra outras destinações (MOTTIAR; TUCKER, 2007). 
A formação de redes na gestão e planejamento de destinos turísticos pode servir como um excelente instrumento de desenvolvimento. Contudo, é necessário que os atores de uma rede identifiquem pontos de interesse comuns e ações que possam ser realizadas, lembrando que tais objetivos e ações devem trazer benefícios a todos os participantes. Caso negativo, uma rede pode não ser bem-sucedida. (FLECHA et al., 2012). A aproximação e as ações de cooperação em rede têm como base a informação e conhecimento, sem haver troca de informação, compartilhamento de experiências, aprendizado conjunto ou ação coletiva, a rede se enfraquece, e novamente sua existência perde a finalidade, para a qual Alves $(2011$, p. 52) aponta: “[...] a constituição de redes, em seus diferentes níveis e aplicações, flexibiliza as relações entre as pessoas, potencializando o compartilhamento de informações entre as organizações e os indivíduos".

Por isso, as ações políticas não podem ignorar as informações que os próprios grupos elaboram a partir de seus espaços locais cotidianos de vivência, interação e trabalho. (MARTELETO; SILVA, 2004, p. 48).

\footnotetext{
As redes vão conectar os agentes envolvidos com a regionalização do turismo e promover o intercâmbio entre os participantes de todas as regiões turísticas. Servirão para fazer surgir soluções, propiciando que essas sejam divulgadas para outros participantes em outros lugares, o que facilitará o acesso à inovação e a difusão dos casos de sucesso. A ideia é aproximar e ligar de forma produtiva os participantes, para que, juntos, eles possam trabalhar para o desenvolvimento do turismo brasileiro. (MINISTÉRIO DO TURISMO, 2007, p. 19).
}

Considera-se ser pertinente pensar uma rede como um elemento que abre um horizonte de possibilidades em relação ao desenvolvimento de um dado território. A ação endógena apresenta definições democráticas, uma vez que, os próprios agentes locais desempenham uma relação autônoma. Nesse caso, a população reconhece sua identidade e é sujeito ativo do desenvolvimento. Como Rambo e Rückert (2008, p. 14) afirmam, a partir dos novos usos políticos e econômicos de um território, é estabelecido um espaço de ação, de exercício de poder e gestão. Nesse território os atores assumem relativo protagonismo no desencadeamento de ações que visam reestruturar e desenvolver seu território.

Essa noção de desenvolvimento valoriza a noção de horizontalidades, que como definido por Santos (2006), aponta que, com base na sociedade territorial, é possível 
encontrar um caminho que se anteponha à globalização perversa e se aproxima da construção do desenvolvimento, nessa concepção a participação efetiva dos atores torna-se prioridade. Ainda, para que o processo de desenvolvimento seja realmente viabilizado este deve ser pautado nos princípios da democracia e cooperação.

Essa noção de desenvolvimento indica uma relação com as interações sociais estabelecidas pelas redes. O desenvolvimento não se constrói apenas a partir de uma vontade explícita dos atores ou de um desejo de transformação; ele está diretamente relacionado com a natureza das relações e a densidade das redes que se formam no âmbito de um local. (ANDION, 2003).

A reflexão sobre o papel das redes, o turismo e sua importância ao desenvolvimento regional, implica também na relação entre rede e território, mas para, além disso, observa-se que é preciso perceber a rede com uma estrutura de interconexão instável, composta de elementos em interação, e cuja variabilidade obedece a alguma regra de funcionamento. (SILVA JÚNIOR, 2007, p. 32).

A análise das redes como estratégias de ações coletivas em busca de transformações políticas, econômicas e sociais, aponta as relações sociais como vetores da própria dinâmica do desenvolvimento regional. Constata-se a importância de uma rede para aumentar a competitividade e fortalecer uma região, no entanto, o setor do turismo ainda enfrenta os desafios da fragmentação e individualização dos interesses. $\mathrm{O}$ simples fato da proximidade geográfica não confere uma atuação em rede. De acordo com o Ministério do Turismo - MTur (2007), a falta de contato entre os agentes envolvidos e a divergência de interesses dificulta a formulação de alternativas sustentáveis para o desenvolvimento dos territórios com base na atividade turística.

\section{CONSIDERAÇÕES FINAIS}

Ações de cooperação em rede estão diretamente relacionadas com o fortalecimento da gestão do território no âmbito regional, a descentralização da gestão, e a promoção de dinâmicas do desenvolvimento regional. Analisa-se uma rede social como uma organização facilitadora para os processos de desenvolvimento. 
Uma rede composta de indivíduos, grupos ou organizações, e sua dinâmica está voltada para a perpetuação, a consolidação e o desenvolvimento das atividades dos seus membros. A horizontalidade no processo e a participação efetiva dos atores envolvidos é o diferencial entre a noção de crescimento e desenvolvimento. Logo, a desconcentração do poder, o caráter democrático e a participação voluntária nas redes opõem-se as situações de concentração do poder na mão de um agente hegemônico como as grandes corporações.

O planejamento e a gestão do turismo com o auxílio das redes sociais possibilitam e podem incentivar a articulação dos atores em processos associativos e cooperativos, os quais articulam a oferta de serviços; buscam uma inserção competitiva nos mercados e a melhoria na capacidade de autogestão; além do uso sustentável dos recursos. Como aborda Fratucci (2011, p. 1483), "el turismo no es el sujeto de los procesos de turistificación sino el resultado de las acciones e interacciones de los diversos agentes sociales que lo producen".

A revisão do papel de cada agente social do turismo nos processos de apropriação dos territórios turísticos e das redes regionais estabelecidas favorece uma nova instância de gestão para o desenvolvimento regional do setor. Entretanto, tais redes somente contribuirão para o desenvolvimento turístico no caso de serem frutos de processos democráticos, participativos e inclusivos.

Por fim, analisar as transformações na dinâmica de produção do desenvolvimento regional, na perspectiva da organização e cooperação em redes sociais para potencializar a atividade turística - a fim de verificar, a relação dessas redes com a promoção do desenvolvimento - constitui uma temática que ainda carece de mais e estudos e pesquisas empíricas em diferentes regiões do território brasileiro.

\section{REFERÊNCIAS}

ALVES, L. de M. Redes sociais: uma busca pela temática na área da geografia. In: V ENCONTRO DE PRODUÇÃO CIENTÍFICA E TECNOLÓGICA, 2010, Campo Mourão, Paraná. Anais... Paraná: FELCICAM. Disponível em: <http://www.fecilcam.br/nupem/anais_v_epct/PDF/ciencias_sociais/01_ALVES.pdf>. Acesso em: 20/12/2016. 
ALVES, M. M. O Papel das redes sociais no turismo: uma análise da situação das agências de turismo no Distrito Federal. 153 p. (Dissertação de Mestrado) Centro de Excelência em Turismo. Mestrado Profissional em Turismo, Universidade Federal de Brasília. 2011.

ANDION, C. Análise de redes e desenvolvimento local sustentável. RAP, v. 37 (5), p. 1033-1054, set./out. 2003. Disponível em:

<http://bibliotecadigital.fgv.br/ojs/index.php/rap/article/viewFile/6512/5096>. Acesso em: 20/12/2016.

ANDRIGHI, F. F.; HOFFMANN, V. E. Redes e Cooperação na Destinação Turística de Urubici/SC. Turismo em análise, v. 21, n. 1, p. 149-164, dez. 2010. Disponível em: <http://www.revistas.usp.br/rta/article/view/14210/16028>. Acesso em: 20/12/2016.

BANDEIRA, P. Uma Experiência de Institucionalização de Regiões no Brasil: Os COREDEs do Rio Grande do Sul. FÓRUM DOS CONSELHOS REGIONAIS DE DESENVOLVIMENTO, 2010, Rio Grande do Sul. Anais... Rio Grande do Sul: Passografic. p. 111-162.,. Disponível em:

<http://www2.al.rs.gov.br/forumdemocratico/LinkClick.aspx?fileticket=ZLSG7e8ceE\%3D\&tabid=5363\&mid=7972>. Acesso em: 20/12/2016.

BOISER, S. La construcción social del regionalismo latinoamericano (Escenas, discursos y actores). Revista del CLAD Reforma y Democracia, Caracas, n. 2, p. 119, jul. 1994. Disponível em: <http://old.clad.org/portal/publicaciones-del-clad/revistaclad-reforma-democracia/articulos/002-julio-1994/la-construccion-social-delregionalismo-latinoamericano-escenas-discursos-y-actores>. Acesso: 20/12/2016

CASTELLS, M. A sociedade em rede. São Paulo: Ed. Paz e Terra, 2000.

CORRÊA, R. L. Redes Geográficas: cinco pontos para discussão. In: VASCONCELOS, P. A; SILVA, S. B. M. Novos estudos de geografia urbana brasileira. Salvador: UFBA, 1999. p. 62-75.

DEGENNE, A.; FORSE, M. Introducing Social Networks. London: Sage Publication, 1999.

DIAS, L. C. Os sentidos da rede: notas para discussão. In: DIAS, L.; SILVEIRA, R. (Org.) Redes, sociedades e territórios. Santa Cruz do Sul: Edunisc, 2005, p. 11-28.

Redes: emergência e organização. In: CASTRO, I. E. de; GOMES, P. C. da C.; CORREAA, R. L. Geografia conceitos e temas. 12. ed. Rio de Janeiro: Bertrand Brasil, 2009. p. 141-162

ETGES, V. E. A região no contexto da globalização: o caso do Vale do Rio Pardo. In: VOGT, O; SILVEIRA, R. Vale do Rio Pardo: (re)conhecendo a região. Santa Cruz do Sul: Edunisc. 2001. p. 351-365. 
FLECHA, A. C.; SILVA, A. V. C.; FUSCO, J. P. A.; BERNARDES, A. T. Redes de empresas e seus efeitos sobre o turismo. RAE, São Paulo, v. 52, n. 4, p. 386-406, jul./ago. 2012. Disponível em: <http://rae.fgv.br/rae/vol52-num4-2012/redes-empresasseus-efeitos-sobre-turismo>. Acesso em: 20/12/2016.

FLECHA, A. C.; SILVA, G. P.; BERNARDES, A. T.; PINHEIRO, C. F. S.; MACHADO, R. F. Redes complexas: interações dos atores do setor de turismo na cidade de Ouro Preto. In: SANTOS, C. H. S.; BASSANESI, M. M. R. (orgs.) Turismo e redes: um novo caminho para a organização no início do século XXI. Caxias do Sul: Educs, 2010. p. 1-15.

FRATUCCI, A. C. Proceso de formación de una red regional: Región turística de las Agulhas Negras - RJ - Brasil. Estudyos y perspectivas en turismo, v. 20, p. 14931496, 2011. Disponível em: <http://www.redalyc.org/articulo.oa?id=180722700014>. Acesso em: 20/12/2016.

Refletindo Sobre a Gestão dos Espaços Turísticos: perspectivas para as redes regionais de turismo. Turismo em Análise, v. 20, n. 3, p. 391-408, dez. 2009. Disponível em: <http://www.revistas.usp.br/rta/article/view/14192>. Acesso em: 20/12/2016.

GRANOVETTER, M. The Strength of Weak Ties. The American Journal of Sociology, v. 78, n. 6, p. 1360-1380, maio de 1973.

KNUPP, M. E. C. G.; MAFRA, F. L. N. Redes do Turismo: uma análise da política de turismo do Estado de Minas Gerais - Brasil. Turismo em análise, v. 23, n. 3, p. 663690, dez. 2012. Disponível em:

<www.revistas.usp.br/rta/article/download/52439/56433>. Acesso em: 20/12/2016.

LENCIONI, S. Região e geografia. São Paulo: EDUSP, 1999.

MARTELETO, R. M.; SILVA, A. B. de O. Redes e capital social: o enfoque da informação para o desenvolvimento local. Ci. Inf., Brasília, v. 33, n. 3, p. 41-49, set./dez. 2004. Disponível em: <http://www.scielo.br/pdf/ci/v33n3/a06v33n3.pdf>. Acesso em: 20/12/2016.

MATOS, R. Territórios e redes: dimensões econômico-materiais e redes sociais especiais. In: DIAS, L. C.; FERRARI, M. (orgs.). Territorialidades humanas e redes sociais. Florianópolis: Insular, 2011. p.167-188.

MINISTÉRIO DO TURISMO. Formação de Redes. Brasília: Ministério do Turismo, 2007.

MINISTÉRIO DO TURISMO. Programa de Regionalização do turismo: Diretrizes. Brasília: Ministério do Turismo. 2013. Disponível em: <http://www.turismo.gov.br/images/programas_acoes_home/PROGRAMA_DE_REGI ONALIZACAO_DO_TURISMO_-_DIRETRIZES.pdf>. Acesso em: 20/12/2016. 
MOTTIAR, Z.; TUCKER, H. Webs of Power: multiple ownership in tourism destinations. Current issues in tourism, v. 10, n. 4, p. 279-817, 2007. Disponível em: $<$ http://arrow.dit.ie/cgi/viewcontent.cgi?article $=1011 \&$ context $=t$ fschhmtart $>$. Acesso em: 20/12/2016.

RAMBO, A. G.; RÜCKERT, A. A. O sistema territorial de Claude Raffestin: para pensar o desenvolvimento territorial. In: ENCONTRO ESTADUAL DE GEOGRAFIA, 28, 2008, Bento Gonçalves. Anais... 2008.

SANTOS, M. Território e Dinheiro. In: Território e Territórios. Niterói: Programa de Pós Graduação em Geografia - PPGEO-UFF/AGB, 2002. P. 7-13.

A natureza do espaço: técnica e tempo, razão e emoção. 4. ed. 2 reimp. São Paulo: EDUSP, 2006.

SCHERER-WARREN, I. Redes Sociais: Trajetórias e Fronteiras. In: DIAS, L.C.; SILVEIRA, R. L. L. (Org.) Redes, sociedades e territórios. EDUNISC, 2007. p. 2950 .

SCHLITHLER, C. R. B. Redes Intersetoriais de Desenvolvimento Comunitário. 2010. Disponível em: <http://idis.org.br/wp-content/uploads/2014/04/Redes-intersetoriais-edesenvolvimento-comunit\%C3\%A1rio.pdf>. Acesso em: 20/12/2016.

SILVA JÚNIOR, A. S. S. Redes técnicas, turismo e desenvolvimento sócio-espacial na Ilha do Mosqueiro - Belém- PA. 119 p. (Dissertação de Mestrado). Programa de Pós-Graduação em Geografia. Universidade Federal do Pará Belém, 2007.

SILVEIRA, M. L. Região e Globalização: pensando um esquema de análise lobalização: pensando um esquema. Redes, Santa Cruz do Sul, v. 15, n. 1, p. 74-88, jan./abr. 2010. Disponível em:

<https://online.unisc.br/seer/index.php/redes/issue/view/71>. Acesso em: 20/12/2016.

Recebido em: 07-05-2014.

Aprovado em: 06-06-2014. 